\title{
HAY LUGAR PARA LOS DÉBILES. CONFIGURACIONES DE LA VIOLENCIA EN EL CHACO ARGENTINO: GÉNERO NEGRO, SUBJETIVIDADES Y ESPACIO*
}

\author{
Francisco Gelman Constantin \\ Instituto de Literatura Hispanoamericana (UBA) - Conicet \\ fgelmanc@filo.uba.ar/simbiosisficticia@hotmail.com
}

\section{RESUMEN / ABSTRACT}

Este artículo investiga la emergencia y la expansión del género negro en la literatura del Chaco argentino, considerando especialmente el modo en que esos textos configuran experiencias de la violencia, subjetividades y espacios. A tales fines, analiza cuentos y novelas entre las décadas de 1960 y 2010, en correlación con otros discursos sociales y prácticas culturales. Reciben particular atención las novelas de Mempo Giardinelli, Carlos Busqued y Mariano Quirós, en sus vínculos con la violencia de Estado del último proceso dictatorial en Argentina y las transformaciones urbanas correlativas a la expansión continental del neoliberalismo.

PALABRAS CLAVE: Chaco argentino, género negro, violencia, subjetividad, espacio.

This article addresses the emergency and broadening of hard boiled fiction in Argentinean Chaco literature, stressing ways in which such literature shapes experiences of violence, subjectivities and spaces. The study considers a corpus of short stories and novels published between the 1960s and the 2010s, in connection to other social discourses and cultural practices. Consideration is given to novels by Mempo Giardinelli, Carlos Busqued and Mariano Quirós

Este artículo es producto de mi investigación en el marco del proyecto "La experiencia de las víctimas y los relatos de la violencia”, dirigido por Ana María Zubieta, en la Universidad de Buenos Aires; quiero agradecer especialmente a sus demás exintegrantes e integrantes por las discusiones y la convivialidad. También deseo dar particulares gracias a Silvia Delfino, cuya generosidad en las palabras enriqueció este trabajo de un modo imposible de sobrestimar. 
as they relate to State violence in the last Argentinean dictatorship and the shifts in the urban texture as a result of the continental expansion of Neoliberalism.

KEY WORDS: Argentinean Chaco, hard boiled, violence, subjectivity, space.

Regresó a la cama, encendió otro cigarrillo y se recostó para fumarlo. Entender. Al menos entender. Entender por qué y cómo su vida se había arruinado en sólo tres noches de calor, de aire

tórrido. Carajo, pues porque había vuelto al Chaco, ¿no? Y el Chaco es tierra caliente, trópico, selva, monte, gente apasionada.

Mempo Giardinelli, Luna caliente

En una ciudad turística, una habitación de hotel. Suena un disparo en la mitad de la noche. Quien dispara es un cadete de policía recién graduado. De entre la confusión imperante, un periodista encargado del caso logra enterarse de que el baleado es otro cadete, compañero del primero en la academia y-como él- asignado hace poco a la ciudad.

Como contratapa de un libro o como sumario de una película, cualquier lector, cualquier televidente puede reconocer inmediatamente que estamos en las coordenadas del género negro. La historia, sin embargo, proviene de una sintética crónica en un diario porteño (Página/12, 9 de junio de 2012, "Muerte entre policías"): el hard boiled ha salido hace rato de las fronteras de la literatura en sentido estrecho -acaso desde su constitución ha objetado la consistencia de esa fractura (Link 6)-e integra los modos en que la comunidad configura su experiencia de la violencia desde las más variadas instancias de enunciación y acción. Entender cómo damos forma hoy a nuestra experiencia de la violencia requiere, por tanto, comprender de qué modo el género negro interviene en esos entramados.

Herederos de Fredric Jameson, no podemos entender la aproximación reflexiva a un género sino como el estudio de una dispersión histórica de formas; hablar de una matriz genérica es referirse a cristalizaciones momentáneas en una serie diacrónica de variaciones estéticas y sociales indefinidas. Intentamos captar, entonces, las transformaciones que introduce el género negro sobre las configuraciones de la violencia, a partir de una serie de instantes en un fenómeno acotado de algún modo: qué ocurre cuando en las narrativas de la violencia la relación entre crimen y ley toma la forma no de la oposición 
entre la racionalidad jurídica del Estado y una discontinuidad a ser resuelta por el razonamiento, sino de una práctica económica y las técnicas policíacas que la administran y reconducen numéricamente (Link 8; Foucault, Seguridad 48-51, 74-7, 315).

Elegimos aquí, para empezar, la emergencia de la narrativa negra a partir de los relatos regionalistas de cuchilleros en la literatura del Chaco argentino ${ }^{1}$ : ¿qué subjetividades y qué formas de organización del espacio se anudan a la violencia cuando se produce esa transformación en un medio literario particular, del enfrentamiento por honor de dos personajes de los márgenes (a propósito de una mujer, acaso de una ofensa pública) a la entrada progresiva en el horizonte de la novela y el cuento hard bolied?

La pregunta debe formularse aquí en términos afines al Michel Foucault de “La vida de los hombres infames” y “¿Qué es un autor?”: los discursos no son emisiones de sujetos preexistentes que les sirvan de soporte, sino que los enunciados participan de la organización de un escenario de disputas dentro del cual acontecen las formas de subjetividad ${ }^{2}$. En nuestro caso, no ya ¿cómo representa la literatura en clave negra los individuos integrados a su narración?, sino más bien ¿cómo intervienen estos cuentos y novelas sobre las posibilidades de constitución de las subjetividades de la violencia?, ¿qué efectos tiene la ocurrencia del género negro sobre los formas disponibles en una comunidad para constituirse como criminal?

En el mismo sentido, no caben aquí preguntas del tipo de ¿cómo se representa el Chaco en estos textos? o ¿qué tipo de representaciones de la violencia demanda un espacio empírico de tales o cuales características?, sino más bien, ¿qué transformaciones sobre la configuración del Chaco argentino introducen los nuevos textos?, ¿qué nuevos modos de circular por el territorio hacen posibles o legítimos?, ¿qué nuevas residencias de la violencia permiten imaginar?

El momento por el que conviene empezar es la década de 1960. A ella pertenecen los cuentos de Hugo del Rosso, Domingo Mancuso, Ricardo Ríos

\footnotetext{
Respecto de las complejidades conceptuales involucradas en la noción de emergencia de un género, El género gauchesco. Un tratado sobre la patria es iluminador en muchos sentidos (Ludmer 11-4), por mucho que la noción de "límite" sobre la que se apoya resulte algo estrecha en las coordenadas de esta investigación, cambio de perspectiva que involucra tanto a Jameson como a Michel de Certeau, como se verá.

La reconstrucción sistemática de los artículos de Foucault bajo esta óptica puede buscarse en Giorgio Agamben.
} 
Ortiz, Juan José Rivas y Horacio Riveros Sosa reunidos por Osvaldo Pérez Chávez en Narradores actuales del Nordeste, así como el libro de cuentos de Carmen Lila Quevedo, Llamada María. Aunque como entrada en la literatura policial la fecha puede parecer tardía ${ }^{3}$, lo decisivo es que el caso chaqueño no implica la salida de la literatura regionalista hacia el policial clásico de clivaje racionalista-cientificista (núcleo de la literatura policial más característica en Argentina, en buena medida porteña o de las grandes ciudades del interior, como Rosario o Córdoba, pero de ningún modo recluida en ellas, como el nombre de Horacio Quiroga alcanzaría para sugerir), sino el ingreso en la variante negra, que -si los nombres de Dashiell Hammett y Raymond Chandler han de decirnos algo- debe ubicarse a nivel mundial bastante más adelante en el tiempo.

Mientras el duelo de valientes deja el paso a las redes de prostitución, los secuestros y el crimen organizado, hay una honda transformación social del Chaco argentino entre manos, que involucra el auge algodonero (desplazando el quebrachal) y sus efectos demográficos, el retiro de la zona del Ejército Nacional con la consolidación de las reducciones, así como más adelante la provincialización del Chaco (Iñigo Carrera y Podestá; Mari) ${ }^{4}$. Con todo, por formularlo en términos genéricos, alguna singularidad en clave negra se trama ya en tiempos de cuchilleros cuando la selva y el contrabando condimentan la imaginación regional del crimen: parafraseando a Mariano Quirós, la experiencia del territorio chaqueño sugiere un vínculo necesario entre sordidez y frontera (Zunini s/p). El dinamismo social no puede remitirse

3 Máxime si hubiera de suscribirse la tesis de Román Setton, que ubica en el período 1877-1912 el inicio de la narrativa policial en Argentina, en polémica con aquella tradición que lo ha ubicado -atendiendo sobre todo a los manifiestos de Borges y Bioy- en la década de 1940 (Setton 11-2 et passim).

$4 \quad$ Las aserciones de Oscar E. Mari deben contextualizarse en una investigación que presupone la justificación, desde el punto de vista de la moral, del ejercicio represivo y disciplinario de las instituciones estatales, con acuerdo a la defensa de la propiedad y "el orden público”. Bajo tal punto de vista -por ejemplo- lo que este trabajo concibe como la sujeción de los pueblos originarios recibe el nombre eufemístico de "ocupación y pacificación de estas regiones" (Mari 9). Vale notar la distancia crítica imprescindible, por tanto, en su lectura. Con todo, debidamente puestos en correlación con investigaciones con otras perspectivas, el acceso de Mari a archivos policiales y otras documentaciones semejantes, así como la extensión y el detalle de sus análisis lo hacen una herramienta valiosa de la investigación. Por otra parte, en tanto material cultural local, ocupa él mismo una posición iluminadora del campo de debates sociales sobre el que intervienen las novelas que analizaremos luego. 
a algún equilibrio legal racional subyacente, siquiera como proyecto, sino que el circuito vertiginoso de los intercambios entre sombras (las sombras que proyecta la fronda) es la condición de partida, que impide desde un principio el cuajado de una lógica policial a la inglesa: "La selva había impuesto su ley, que no es la sabia y meditada de los hombres" (Pérez Chávez 61). La ley de la selva es la regularidad de la vorágine en la que ninguna comunidad transparente puede constituirse ${ }^{5}$, es una cotidianeidad de lo irregular en la que el enfrentamiento de dos valientes nunca acaba de saldar las cuentas y reestablecer el orden. No porque haya alguna especie en la flora autóctona que dispare al aire un polen hard boiled, sino porque a la experiencia colectiva que hace del quebrachal chaqueño una selva y de la economía local contrabando le repugna la forma del enigma. El duelo de cuchillos se inclina irrefrenablemente hacia el género negro -que acaba por coagular en los años sesenta y sigue transformándose hasta el siglo XXI- a medida que se urbaniza y se altera la lógica del espacio, así como se modifica el régimen de subjetividades que le corresponde, pero la inteligibilidad positivista nunca amenaza con entrometerse: no hay lugar para Watson ${ }^{6}$.

En "Cuando la selva aprisiona", escrito por Horacio Riveros Sosa en 1966, la transformación social y estética escribe su propia historia bajo la forma de una biografía individual entre la cuchillada de la honra y el empellón que protege la propiedad. La vida del protagonista, Lorenzo Rivas apodado “Gauchillo", efectúa como trayecto personal la migración entre los dos polos. Hijo del capataz de una estancia ganadera, poco dado a los trabajos del campo pero "bien parecido" (Pérez Chávez 205-6), escapa de la policía con su enamorada Mariana hacia Resistencia, donde la vida en pareja pronto se le hace insostenible, y acaba partiendo solo para ejercer trabajos varios entre

5 A propósito del modo en el que las narraciones literarias y no literarias median en la configuración de imágenes de opacidad o transparencia de lo social, cfr. Williams (passim).

Por lo que respecta a la ausencia de una imagen de equilibrio preexistente en su relación con la imposible constitución del policial clásico, cabe considerar la alternativa a lo que sugiere esta genealogía literaria, en consonancia con otras intervenciones culturales que le son solidarias. Oscar E. Mari ilustra involuntariamente las necesarias paradojas de la concepción inversa cuando pretende que "la cuestión indígena (...) fuera el factor desequilibrante del sistema durante las primeras décadas de vida territoriana” (10). Como se verá, lo que está en juego en Mari es la pretensión de la anterioridad de una comunidad criolla estable, cuyo bienestar habría perturbado la irrupción (¿desde allende los mares?) de los pueblos originarios. Parece, por tanto, una alternativa más verosímil la exclusión de la imagen de equilibrio primitivo que propone Mari, con acuerdo a lo que nos sugiere la literatura de la zona. 
la selva, las estancias y el desierto chaqueños. A medida que se aproxima y se aleja de la ciudad desde el pago, el desierto y el quebrachal, oscilando entre su nombre legal y su apodo de cuchillero, pierde y recupera el coraje, circula por el horizonte sin cotas o se encierra con su amor en una pensión decadente a guarecerse de las exigencias materiales, defiende su orgullo o suscribe la inmediata violencia que requiere obtener el sustento material por vías ilícitas. Los contactos contradictorios entre experiencias diferentes de la vida en comunidad y de sus espacios encuentran en la cohesión de su biografía alguna continuidad, el titubeo es la marca del pasaje entre las dos matrices genéricas, es decir de la inscripción en un imaginario en crisis. Los viajes en colectivo y caballo señalan el hiato que separa unos y otros ámbitos, unos y otros modos de subsistencia, una y otra lógica de la violencia.

De acuerdo con Oscar E. Mari, el umbral del crimen organizado en el Chaco argentino debe ubicarse en la década de 1920; pero surge de su propio análisis que se trata todavía de una dinámica personalizada, todavía imbricada con el asesinato por honor y sostenida en la vigencia mítica del criminal afamado, en la estela de bandoleros romantizados como Segundo Peralta, apodado célebremente "Mate Cocido" (67-70). Solo más adelante, mediando la creación de la Gendarmería Nacional Militarizada y las transformaciones sociales antes discutidas, puede reconocerse el desplazamiento de los itinerarios del crimen entre los que medra el género negro.

Cuando la mudanza se completa, el coraje individual termina de desaparecer. Ese es el reumatismo que aflige al narrador y protagonista de "La respuesta", de Carmen Lila Quevedo (36); la postración captura la crisis de la espontaneidad subjetiva de la violencia en el imaginario chaqueño. El relato toma la orfandad como punto de partida, de la que hace seguir el ingreso del protagonista a un "Hogar de desamparados" que hace las veces de encarcelamiento; entre la sumisión a la brutalidad de los celadores y al dolor del reumatismo el yo hace su camino de supervivencia hasta que logra escaparse. El ruego por trabajo en el bar "Los Murciélagos" lo lleva a emplearse como matón de un narcotraficante y proxeneta; la distancia entre un matón a sueldo y un duelista se mide en la conversación que mantiene con el dueño del local:

-Patrón, ¿no se cansa de todo esto?

-Es mi mundo, el mundo del delito, en él nací y en él voy a morir, vos también pertenecés a todo esto, ¡lástima, no! que seas enclenque. (Quevedo 35) 
La debilidad de constitución que se presenta como un atributo individual condensa en realidad una transformación histórica en los modos de subjetivación disponibles en una comunidad. El crimen se adjunta a su ejecutor como una imposición externa, al punto de que el narrador de "La respuesta" prescinda de atribuirse a sí mismo incluso los asesinatos que lo convierten pronto en el jefe de la red criminal. Apenas si se reconoce responsable del eventual estrangulamiento del más cruel de los celadores del hogar de su juventud, para enterarse poco después de que era su propio padre: donde, excepcionalmente, el cuerpo ejecutor del delito se siente propio, la consciencia resulta ser ajena. No hay lugar para John Wayne.

El género negro como reuma de los sujetos de la violencia se expande desbridado hacia los textos contemporáneos: la fiebre de Ramiro en Luna caliente, de Mempo Giardinelli, las jaquecas y los cuerpos narcotizados o supliciados en Bajo este sol tremendo, de Carlos Busqued, las resacas de padre e hijo en Río Negro, de Mariano Quirós. En el compromiso físico se captura la progresiva mutación de esos seres, de sujetos que optan a conciencia por una violencia instauradora de justicia a objetos casi pasivos de una red anónima de violencia arrasadora; la inmersión en el género negro tan pronto como colabora en la invención de la víctima circunstancial, mitiga la figura del criminal, cuya espontaneidad desaparece en beneficio de la sumisión a la ley de la selva, es decir, la ley del hampa. En este sentido ha declarado Quirós, comparando sus narraciones con las películas de Ethan y Joel Coen, que los suyos son personajes a quienes "se les va todo de las manos" ("La literatura chaqueña” s/p). Mientras el cuchillero se constituye como sujeto por el acto de aceptación voluntaria de las determinaciones materiales (la inevitabilidad honrosa de batirse), el criminal y la víctima del hard boiled ingresan a la trama cuando se extravían en ella, cuando ya no pueden decidir sobre sí; son sujetos porque pueden apenas decir su enajenación por parte del vórtice de violencia ${ }^{7}$.

Decir y mirar: los sujetos doblegados de cuyo acontecer participa el género negro son también espectadores de la desventura propia y ajena. La

\footnotetext{
En un sentido más amplio, pero convergente, se ha dicho respecto de los personajes de Busqued: "La estructura que sostiene al sujeto está profundamente conmovida y sin embargo ellos no parecen conmoverse" (Stegmayer y González 7). Curiosamente, cuando el propio Giardinelli ubica la ficción del Far West en el origen del género negro sin acentuar la mudanza (Nichols 496), oblitera aquello que las alteraciones en términos de organización literaria de héroes implican respecto de la transformación en las condiciones históricas de subjetivación.
} 
actitud estetizante del narrador de Río Negro ante la costa de Resistencia, que explora y describe regocijándose, progresivamente se traslada hacia el panorama de la violencia, a medida que la muerte accidental y el asesinato pasan a ser la nota dominante. Cerca del final de la novela, el protagonista escritor reflexiona sobre la muerte del teniente que ha querido interrogarlo por su lesión a una prostituta (la hermana del oficial de policía), al que su empleada doméstica Irma ha asesinado poco antes, y de la amiga de su hijo, intoxicada con farmacéuticos:

Medina, qué mala suerte. Su cuerpo está tendido bocabajo, con el pico incrustado en la cabeza, y nuestro pasto luce ahora un manto rojizo de sangre. Nos quedamos mirando el paisaje, a Medina tumbado aquí, a Mariel un poco más allá, incluso a mí mismo, todo sucio de sangre (Quirós 169).

La adopción de los cuerpos sin vida como objetos de contemplación estética indistintos del paisaje físico forma parte de la destitución de quien observa como sujeto volitivo de la violencia que ha provocado la muerte. En Bajo este sol tremendo, la ampliación de la posición de espectador ya se encuentra realizada desde el comienzo; la mirada pasa insensiblemente de los documentales zoológicos a la pornografía gore (registro fílmico del suplicio sexual), y a la violencia generalizada de la que se es también ejecutor; con la mediación del título de uno de esos videos, “Extreme German Tortures 5", la novela adjunta a los tormentos de la industria audiovisual del sexo aquellos otros perpetrados por el nazismo, la dictadura argentina y los protagonistas de la novela, todos disponibles a la misma contemplación impasible del esteta o el curioso.

Si un sujeto se ubica en el umbral del texto bajo condición de poder establecer con él alguna relación imaginaria de utilidad, la mudanza en las formas de subjetividad de la violencia implicadas en el proceso de transformación social y estética en el Chaco argentino supone también un movimiento de la energía intencional de las narraciones (vale decir, cómo alguien podría imaginarse usuario de un relato). Desde otro punto de vista, el discurso forma parte orgánica de las instituciones colectivas que gestionan la circulación de la violencia (Foucault, Seguridad y “La vida...”); pero esas instituciones están sujetas a cambios históricos fundamentales. Tanto desde un punto vista subjetivo, cuanto desde el punto de vista de las tecnologías de poder institucionalizadas, del relato de un duelo entre valientes al género negro se alteran los fundamentos de la relación del texto con la vida. 
El relato de cuchilleros se inserta en una crematística de la fama; así, por ejemplo, en "Donde hay yeguas, potros nacen”, de Domingo Mancuso, en el que la matriz tradicional duelística sobrevive de manera más nítida, se advierte la gravitación del vínculo del nombre al “coraje” legendario, que se elabora en la conversaciones entre conocidos o desconocidos en el interior de las fondas. Del otro lado del mostrador, el propietario del local cuida sus intereses en función de lo que los demás le han hecho saber:

Sabía que el morocho grandote como un rancho, barbilampiño, de pelo largo, cerdoso y renegrido, que estaba sentado ante la mesa en mangas de camisa, con rojo pañuelo de seda al cuello y el látigo de carrero alrededor del respaldo de la silla, se llamaba Juan Bedoya, a quien los peones llamaban respetuosamente don Juan por la fuerza hercúlea que poseía, su espíritu pendenciero y sus antecedentes de matón, que aunque no muy honorables a los ojos de la ley, le habían ganado indiscutido prestigio en el ambiente semi-bárbaro del obraje (Pérez Chávez 87).

El relato de la fama concentra entre la descripción y la narración todo aquello que lo hace imprescindible para el colectivo: las señas para reconocer al individuo, el nombre, el tipo de acciones que se le atribuyen y el estatuto jurídico respecto de la ley estatal y el veredicto de la comunidad. Las discusiones entre copas producen el valor de justicia o injusticia de las acciones de los protagonistas de esas historias en colaboración y competencia con las intervenciones de la policía, así como conceden a los individuos prestigio o desprestigio.

Por el contrario, el secreto implicado en el crimen organizado sustrae la narración del circuito de la fama y la justicia, y deja vacante la fundamentación para el individuo y el colectivo (es decir, para los sujetos de la imaginación comunitaria). En el género negro la escena que modela la enunciación y la explica simbólicamente no puede ser ya el relato oral privado en la querencia, y pasa en cambio a obtener su valor de la forma del testimonio judicial: se escribe como se declararía a un juez, exculpando o exculpándose de los excesos a los que obliga la omnipotente pendiente del crimen.

Lo que estaba haciendo era horrible, lo sabía, era completamente consciente. Pero no tenía opciones. Perdido por perdido... Sí, estaba jugado y ahora ya nada lo detendría.

Él no había querido matar a Araceli. Dios, claro que no, había querido amarla, pero... Bueno, ella se resistió, sí, y él en realidad no debió... pero bueno, mejor no pensar. Perdido por perdido, bien jodido, el polvo 
más costoso de mi vida, se dijo. Se espantó de su propio chiste. Soy un monstruo, súbitamente un monstruo. La culpa ha sido de la luna. Demasiado caliente, la luna de Chaco. Sobre todo, después de ocho años de ausencia. Perdido por perdido, estaba jugado (Giardinelli 48).

La apología dubitativa del protagonista de Luna caliente respecto de la violación y el supuesto homicidio de una adolescente es la confesión de un reo, que reconoce en sesión sus crímenes, para mitigar su pena. Ramiro convalida, hablándole, la ley por la que se lo juzgará y su identificación como criminal, bajo condición de obtener un perdón. En contrapunto estricto con la discursividad pública que insiste en moralizar la ley e inmoralizar al delincuente -así como el régimen el coraje en la literatura de cuchilleros moralizaba la represión de las comunidades originarias-, el criminal del hard boiled hace de su acción una falta a la norma bajo condición de suspender el juicio moral a cambio de una responsabilidad inimputable, orgánica o natural: la luna, la temperatura, la "condición humana" (Giardinelli 80-81).

De los relatos de la década del sesenta a las tres novelas de la década de 1980 en adelante, la transformación en los modos de configurar la experiencia de la violencia involucra muy especialmente la vivencia de la represión, tortura y desaparición de personas durante el gobierno de María Estela Martínez de Perón y el último proceso dictatorial argentino, entre 1974 y 1983; la persecución y la violencia se organizan literariamente como marcas generacionales que afectan a la pertinencia cultural del género negro (Zubieta 45). La consideración de ese aspecto debe reconocer la singularidad regional del fenómeno nacional -y en definitiva continental-, por cuanto la memoria e historias locales implican peculiaridades en las formas de organización comunitaria que no pueden extrapolarse de un lugar a otro (Calvo s/p). La violencia estatal y paraestatal sobre el sindicalismo industrial, la insurgencia urbana y las ligas agrarias en el Chaco adquiere una gravitación regional específica sobre imaginarios y discursos, bajo la forma de una figuración ambivalente de las formas de asociación gremial y política, en la que los enunciados de legitimación de la represión siguen ejerciendo efectos indirectos (Calvo s/p). Las novelas de Giardinelli, Busqued y Quirós coinciden en principio en la deslegitimación absoluta del Estado como ponderador ético, toda vez que su lazo con el totalitarismo y el crimen organizado es indiscutible, pero al mismo tiempo presuponen el descrédito de los colectivos políticos contestatarios.

En ese posicionamiento entra en juego una determinada interpretación de la discursividad pública de su tiempo; por caso, Quirós declara abiertamente 
radicar su escritura, en tanto intervención literaria sobre la violencia, en relación con los testimonios de sobrevivientes y diversas escrituras literarias del "desbarajuste que provocaron las dictaduras latinoamericanas" (Paredes $\mathrm{s} / \mathrm{p}$ ). Quirós entrama la configuración de los personajes de sus narraciones con ese diagnóstico histórico-político legible en las entrevistas que le han hecho. La identidad del narrador protagonista de Río Negro y su mujer depende de su abandono de la organización Montoneros en la juventud, luego del ridículo episodio en el que intentan incendiar el automóvil de un comisario estacionado en una plaza de Resistencia y fracasan por no imaginarse la posibilidad de que esté blindado. Mientras el narrador se aleja del coche del comisario Medina, decepcionado, asume la condición de su ingreso a la novela: "Hacía calor en Resistencia y mientras caminaba decidí que mi etapa de subversivo había terminado" (Quirós 18). Se es criminal cuando (y donde) ya no se puede más ser insurgente o -como los Medina (el padre, comisario torturador; el hijo, teniente proxeneta) en la misma novela o Daniel Molina y Duarte en la novela de Busqued-se pasa a retiro (luego de haber torturado integrantes del Ejército Revolucionario del Pueblo, bajo órdenes de la Fuerza Aérea o la policía provincial).

Las novelas configuran una experiencia de la vida en común donde las instituciones represivas estatales, además de involucrarse a gran escala en proyectos criminales, no se hacen presentes para asegurar derechos o resguardar a la población. El teniente Molina de Río Negro atiende una denuncia solo porque proviene de su hermana y su novia (probablemente explotadas sexualmente por él), el policía que recibe a Certati en Bajo este sol tremendo para tomarle testimonio sobre su madre y su hermano asesinados es un simple burócrata, los policías de Luna caliente solo están interesados en el éxito de sus carreras. En este contexto, para Damián Selci “en las obras de Busqued, Falco y Lamberti no hay Estado de Derecho, o es raquítico, y de esa percepción exacta de la historia argentina reciente se deduce que la violencia tenga que aparecer en su desnuda inmediatez, precisamente porque la Mediación que recorre a la sociedad civil, el Estado, se ha limitado a la inacción o a la represión" (Selci 23). Pero las mayúsculas de Selci desdibujan el problema que involucra la relación entre el Estado y el estado de derecho: que los aparatos estatales no se ocupen de proteger a la sociedad civil no implica que se hayan sustraído de escena, así como tampoco corresponde identificar su intervención exclusivamente con la represión entendida en un sentido estrecho (Foucault Vigilar y Seguridad). Resulta imposible inferir en estos textos que el Estado y sus fuerzas represivas, del totalitarismo 
dictatorial al "gatillo fácil”, la prostitución y el secuestro extorsivo, sean inactivos o apenas ocasionalmente violentos. La industria del crimen que pone en movimiento la trama negra se sostiene únicamente bajo condición de la regulación estatal activa de la circulación de personas y valores.

La gestión económica de la violencia en términos de seguridad implica una teoría de los flujos territoriales (Foucault, Seguridad), que involucra las disputas contemporáneas por la configuración colectiva del espacio. Si el espacio es por una parte una superficie proyectada por la mirada estatal y la administración de los negocios -o el ejercicio de distintas formas del poder institucionalizado-(Foucault, Seguridad), al mismo tiempo esa superficie es perturbada por el trazo figurativo de los recorridos singulares de los caminantes civiles, reescrita por sus atajos y desvíos (De Certeau 103-09). Gilles Deleuze y Félix Guattari formulan la contestación de las determinaciones opresivas del espacio como elogio de la fuite en avant, resistencia a la clasificatoria estatal por medio del recurso a la fuga. Pero la oposición entre Estado y nomadismo podría involucrar una imagen demasiado estrecha de las disputas políticas en juego.

Una contestación al modo en que Mille platteaux usa su propio ensayo sobre Lucrecio para argumentar su política programática del flujo (Deleuze y Guattari 446-47), puede encontrarse en Atlas de Michel Serres, si se lo lee de la mano de los textos argentinos aquí considerados. De acuerdo con Serres, el alcance de la desterritorialización de Deleuze y Guattari se limita a una experiencia disponible y deseable solo para algunos. Hay unos pocos para los que la globalización hace posible la liberación respecto del lugar propio como desidentificación progresiva, pero la multitud de los miserables debe en cambio luchar esforzadamente en el fárrago de la fluidez por hacerse siquiera un hábitat mínimo para mantenerse en la condición humana (Serres 42-54). La vivencia mayoritaria de una aspiración de configuración del espacio no es la del borramiento de las estrías del poder estatal, sino la de la conquista de una multitud de residencias vitales y enunciativas mínimas que resguarden del torrente acelerado de los circuitos de brutal dominación económica y política. Poner reparos a la comprensividad de las tesis de Deleuze y Guattari no implica descartar la existencia de una violencia de la fijación territorial, sino comprender hasta qué punto tanto la fijación por la fuerza cuanto el desplazamiento pueden imbricarse con constricciones económicas y represivas. La complejidad de esos anudamientos organiza la historia chaqueña. 
Las recordadas masacres de 1923-1924 en Napalpí pueden ser una indicación sugerente en este sentido. Entre esos dos años, la policía chaqueña, los colonos algodoneros y los braceros de las comunidades originarias protagonizaron una serie de enfrentamientos con centenares de muertos entre los últimos y algunas decenas entre los dos primeros grupos, desencadenados por los violentos intentos de los grandes productores locales en colusión con el aparato represivo del Estado de retener por la fuerza a los trabajadores golondrina para impedir su migración a los ingenios de Salta y Jujuy. El cierre del proceso corresponde al episodio de "La Matanza", en el que la policía chaqueña reprime brutalmente la reducción de Napalpí, asesinando a unos doscientos de sus habitantes y liquidando la historia de conflictos entre colonos y braceros (Mari 63-66); con ello se agota la frontera cultural como residencia privilegiada de los conflictos sociales violentos y se instala la dinámica clasista, en virtud de la definitiva proletarización de los pequeños campesinos y la población de las reducciones (Iñigo Carrera y Podestá 7-8, $24-25,32-34)$. Lo que salta a la vista en el proceso es que ni la violencia ni el acicate económico pueden identificarse abstractamente con la lógica de asentamiento o con la lógica del tránsito, sino que solo experiencias colectivas peculiares pueden refrendar uno u otro anudamiento. Cuando, primero, la sujeción de los pueblo originarios deja de ser la preocupación primordial de los terratenientes y el Estado, y, segundo, se constituye la Gendarmería Nacional como administración militar de la circulación por el espacio ${ }^{8}$, el tránsito deja de ser en sí mismo una amenaza para la normalidad capitalista en el Chaco argentino.

Los vuelcos institucionales a escala nacional de los últimos cuarenta años supusieron en la región transformaciones en las condiciones de la disputa por el ejercicio político del poder territorial y la administración local de los recursos económicos (Natanson 2-3), que repercuten en los modos

\footnotetext{
Por oposición a la Policía, que administra los centros urbanos, la Gendarmería es en efecto la organización represiva de la circulación. De acuerdo con el proyecto de creación que envía Agustín P. Justo al parlamento durante su presidencia, se espera que la Gendarmería Nacional "patrulle los caminos, recorra las regiones y en su carácter de fuerza militarizada lleve a esas tierras [por los territorios nacionales, como el Chaco] la seguridad para sus habitantes" (citado en Mari 160). Con todo, la base territorial en el origen de la propia Policía en el caso chaqueño es dudosa, toda vez que el aparato represivo local se conforma "con baqueanos de la zona", seleccionados en función de "poseer y poder mantener un cabalgadura y en lo posible ser conocedor de la zona” (Mari 26-32); solo más adelante, a medida que Resistencia y otras ciudades menores crecen puede sugerirse una oposición más nítida.
} 
de circulación y habitación disponibles para la comunidad. Esa situación de intrínseca problematicidad del espacio refrenda la importancia de la intervención literaria sobre esos conflictos, interlocutora polémica del "poco sentido de la territorialidad [y] falta de (...) asociativismo" de las principales iniciativas sociales, políticas y económicas de la región (Muscar Bensayag, Alfonso y Torrente 247).

Cuando Pérez Chávez elogia en los narradores reunidos en su antología el profundo "color local" $(11,87)$, entendido como la presencia en los textos de los emblemas naturales de la geografía de la región, ignora de qué modo la modernización del Chaco argentino compromete los modos de relacionarse con el espacio en general, no solo con el espacio urbano ${ }^{9}$. El paisaje de la zona se elabora literariamente como se lo contemplaría desde un tren, más que como podría aparecer en la mirada de un colono a caballo del siglo anterior (incluso cuando el personaje que lo contempla efectivamente lo atraviese sobre una montura, como el Lorenzo de "Cuando la selva aprisiona”), porque el ciclo de transformación de las condiciones del desplazamiento sobre el territorio se ha completado, como parte de un proceso cultural complejo del que esos textos compilados precisamente forman parte. En las palabras de Mariano Quirós: "Resistencia, y toda la provincia del Chaco, es un territorio de una belleza, te diría, no convencional. Es un lugar horrible. Pero tiene la ventaja de que su fealdad le otorga algo cercano a la urgencia” (Pablos s/p). La oposición entre urgencia y color local no se resuelve como un problema de gusto, sino que comporta la mudanza en la experiencia colectiva de cuya modulación participa la sustitución de un género literario por otro.

El vértigo de la violencia que integra la narración en clave negra participa de la organización del espacio en términos de vías de circulación, porque la lógica de la trama hard boiled es al mismo tiempo una lógica del tránsito. Cuando el narrador de Río Negro todavía no sospecha la plasticidad con la que su empleada doméstica intervendrá en el tejido criminal en el que él está inserto, intenta evitar su entrada en la casa, para ocultarle el cadáver de Mariel, la amiga de su hijo:

$9 \quad$ En este sentido, Francisco Romero ha advertido de qué modo la perspectiva urbana de Giardinelli interviene contra el pintoresquismo del regionalismo estereotipado, incorporando la modernización en el entramado de la experiencia local de la violencia mucho más allá del ámbito estricto de la ciudad de Resistencia (Friera s/p). 
trato de comunicarme con Irma. Ya le dije que se tome unos días de descanso, que aproveche que la señora no está y que Miguel y yo nos podemos arreglar solos. Como no me responde, sigo sus recorridas por los pisos de la casa, fregando aquí y allá, un trabajo nada difícil según puedo observar. Dejás la cabeza en blanco y avanzás y avanzás, no hay de qué preocuparse, mañana será igual (Quirós 105; el destacado es mío).

Anticipando el papel de cómplice que adquirirá la mujer, el narrador de la novela encuentra en su comportamiento, sin buscarla ni reconocerla, la clave de su trama. En la consistencia sistemática de la violencia que el género negro tiene como condición de posibilidad, no hay lugar para una restauración retroactiva del orden. La acción circula con un solo sentido, que es el de la complejidad creciente; la salida del territorio pantanoso de la brutal ley de la selva tiene la forma de un acontecimiento fortuito con ribetes fantásticos, de la supervivencia demónica de Araceli en Luna caliente a todos los intentos de homicidio de Ramiro, a la raramente oportuna aparición de Irma en la novela de Quirós, pasando por la vaca en el camino que hace chocar a los protagonistas de Bajo este sol tremendo. No hay salidas orgánicas del espacio hard boiled porque es un territorio definido por una circulación perpetua que condena a la entropía a los transeúntes: avanzar y avanzar.

El Chaco argentino se configura entonces como un detenimiento momentáneo en la vertiginosa ruta que conduce personas y valores del Litoral al Paraguay o a Brasil; solo el flujo imperioso parece darle consistencia como espacio. En esos caminos se instalan las casetas de peaje o los puestos de prefectura; por mucho que la huida sea el movimiento característico de la población que los recorre, imposible ver en esas rutas las líneas de fuga de Deleuze y Guattari. Son más bien modos de circulación ordenados por el ejercicio del poder represivo del Estado y la administración capitalista de la economía que, según se advierte en Bajo este sol tremendo y Luna caliente, no obturan el flujo de la violencia homicida o de los intercambios ilegales, sino que los ajustan a la regulación crematística de la seguridad ${ }^{10}$. La administración

10 Consecuentemente, no habría que sobrestimar el valor utópico de la huida como tránsito por el territorio chaqueño, toda vez que se trata de recorridos convalidados por la normativa extraoficial producida por el Estado y el mercado. Cfr. al respecto el juicio de Graciela Speranza, para quien "[so]lo se respira un poco de aire fresco en la ruta, doble abstracto de las pocas fantasías realizables de huida” (43). 
económico-política del espacio implica principios no sancionados pero en los que los sujetos se reconocen fácilmente; la literatura negra integra los medios indirectos en los que esa normativa se comunica a los sujetos legislados por ella.

El principio fundante de esos modos de circulación regulados ordena la clasificación de los sujetos respecto de la ley. Los grupos de tareas, los "Falcon, verdeclaros, sin patentes y con antenitas de radiocomandos" que encuentra Ramiro en la comisaría en Luna caliente (Giardinelli 89), prescinden de insignias legales para recorrer libremente el territorio; su sustracción a la ley, en tanto grupos parapoliciales comandados por el gobierno de facto, implica que solo los identifiquen las señas conocidas extraoficialmente. Para quienes no integran ellos mismos las fuerzas represivas, la inserción y el prestigio social determinan con cuánta libertad se puede circular por las rutas, a quiénes debe preocuparles ser detenidos a un costado del camino y a quiénes no, según discuten Ramiro y el doctor Tennenbaum a bordo del coche:

El patrullero se estacionó detrás del Ford. (...)

- ¡Carajo, deje esa botella y quédese quieto!

-Me cago en la policía.

- ¡Pero yo no, pelotudo de mierda! -bramó Ramiro, en voz baja, gutural, quitándole la botella de las manos y tirándola al piso del coche-. ¡Quiere que nos caguen a balazos!

-No se muevan -les advirtió una voz, desde el patrullero. Era una voz serena, casi suave; pero autoritaria, muy firme (Giardinelli 37).

La lógica de la circulación de los sujetos estipula la tranquilidad o el desdén de unos, y la ansiedad de otros, porque de un lado están quienes establecen culpabilidades y condenas, y del otro quienes las sufren:

-Deben tener más cuidado; en estos tiempos y a esta hora, cualquier movimiento sospechoso del personal civil, lo hace pasible de estos operativos.

Ramiro se preguntó qué tenía de sospechoso detenerse en la carretera para vomitar, y no pudo evitar un sentimiento de repulsión por ser tratado como "personal civil”. Pero así estaba el país en esos años, le habían contado (Giardinelli 39). 
Unos, movimientos sospechosos; otros, movimientos a un tiempo evidentes e 'invisibles' ${ }^{11}$. Aquellos cuyo desplazamiento cae bajo la mirada de la policía, además de dinero para pagar peajes, deben llevar consigo documentos que los identifiquen, pero por sobre todas las cosas deben respetar la administración de las fronteras: el camino hacia el Paraguay, Brasil o Bolivia queda abierto con condiciones para la entrada de marihuana y especies animales, y para la salida de fugitivos, siempre y cuando el movimiento no se detenga por demasiado tiempo. Aunque Cetarti señala en Bajo este sol tremendo principios más detallados:

En ese lapso descartó comprarse un auto, no le convenía. Con un auto y porro era un problema pasar cualquier frontera, en colectivo era más fácil. Porque también había empezado a pensar en eso: irse del país. Pensó en Brasil, le gustó la idea de estar en la playa y ser extranjero. Escuchar un idioma distinto, no entender a las personas (Busqued 153).

Quiénes, hacia dónde, con cuánto dinero, con qué documentos, con qué transporte, a qué horas del día. El poder estatal y económico dispone toda una casuística de los desplazamiento sobre la base de los aparatos represivos, pero con la necesaria asistencia de los modos indirectos de transmisión -entendido que la mayor parte de las normas no puede escribirse en la ley pública-, de los que forman parte todas las modalidades comunitarias de narración y muy especialmente aquellas que relatan los circuitos del crimen. La urgencia de la transmisión de los principios de circulación se debe a la permanente modificación del código, desde los tiempos en los que las tribus de mepenes condenaban con el empalamiento de cabezas sobre lanzas el tránsito del Paraná (Quirós 33), hasta los reordenamientos contemporáneos de la geografía de clases y la ubicación del comercio sexual en "zonas rojas" (Quirós 49-50; 177-178). Sin vías regulares de transmisión, el insuficiente conocimiento de las mutaciones en la normalización del tránsito puede provocar el extravío de los sujetos, que suscita la alarma de los espectadores acomodados:

Linyeras, sin dudas eran los de antes. (...) Vivían en la orilla, por lo general bajo los puentes, los modestos puentes de Resistencia (...). Con el correr de los años empezaron a salirse de las márgenes del

11 Cfr. a propósito del problema de la visibilidad de los crímenes de Estado durante la última dictadura el proyecto de archivo de León Ferrari "Nosotros no sabíamos”. 
río y se metieron de lleno en la ciudad, confundidos y hasta medio locos, dormidos en los bancos de las plazas o bajo la luz mortecina de los negocios del centro (Quirós 145-46).

Con sus regularidades y sus desquicios, la ordenación sistemática de los flujos de los sujetos, los valores y la violencia, sobrepone a la geografía natural otro paisaje: la acumulación de desperdicios que deja a un costado de los recorridos la circulación, aquello que se estanca. Los putrefactos desperdicios evadidos de las cloacas en Bajo este sol tremendo, los cuerpos que sus asesinos arrojan en el río o los cuerpos de los suicidas en Luna caliente y Río Negro. La modernización equivale a la aceleración del movimiento por el territorio; a mayor velocidad del tránsito (es decir, de la trama de la violencia), mayor decantación de objetos y vidas descartables a un lado de la vía:

Cuando en 1978 construyeron en Resistencia el famoso Puente de los Inmigrantes, hubo quienes dijeron que lo que en verdad se hacía era abrirles nuevas alternativas a los suicidas. Los más sensatos ni siquiera se molestaron en responder: el progreso no necesita defensores. Pero algo de cierto había en aquella advertencia: el Puente de los Inmigrantes, construido en tiempo record -“ciento veinte legendarios días”, describió el gobernador Serrano, interventor militar de entonces- y con sus cuatro metros sobre el río, ostenta un modesto pero regular caudal de suicidas anuales. En principio nadie lo creía, una cosa es matarse arrojándose al Paraná, pero acabar con la propia vida derrumbándose en las aguas del río Negro... sólo una vida inmensamente desgraciada merecería semejante final (Quirós 133-34).

Vidas inmensamente desgraciadas, Serres nos ha ayudado a verlo, son vidas inhóspitas. Sujetos que solo disponen de una residencia final y de la plataforma móvil desde la que arrojarse a ella, sujetos que a duras penas lo siguen siendo. En los espacios de lectura y escritura que configuran, las novelas de Giardinelli, Busqued y Quirós invierten desesperadamente en una alternativa para ese paisaje, que incluso la fugaz pensión de "La selva aprisiona” comenzaba ya a sugerir. Contra la vertiginosa brutalidad del flujo territorial, individuos desposeídos anhelan construirse un refugio en el que todavía poder contarse como hombres ${ }^{12}$. Aquellos "lugares desde donde ejercer la resistencia a esta

12 En un marco en gran medida compartido, Bruno Giachetti ha hablado de las escasas esperanzas que tienen en Bajo este sol tremendo los intentos "por sobrepasar las condiciones más precarias y elementales de vida" (3). 
desintegración" sobre los que ha hablado Juan Terranova (43) no son meros puntos de detención a la huida, sino constituciones políticas de hábitat.

La situación del protagonista de Luna caliente es acaso la más precaria, apenas encuentra reposo en su viejo cuarto en la casa de su madre, o más adelante en un hotel en Asunción; pero aun así sobresale "la habitación de Ramiro como el único espacio protector" (Mateus 2013: s/p), en la que el "sonido monótono y ensoñador" del vaivén del ventilador contrasta con el ritmo del conjunto de la narración (Giardinelli 57).

Pero la consistencia del hábitat resubjetivante respecto de la vorágine de la circulación sin pausa por el espacio chaqueño no puede depender de su aislamiento del exterior, como aquel del que sería garante la propiedad privada. La vivienda de los protagonistas de Río Negro no presta refugio alguno, sino que es uno de los nodos de proliferación de la violencia, sitio de todas las muertes de la novela; espacio hospitalario, en cambio, son las fábricas abandonadas a un costado de las vías, que visitaba la familia de Ema, la madre y mujer de los protagonistas, en su infancia. En la voz de Ema:

cuando llegábamos a la zona de las fábricas abandonadas, el juego mío y de mi hermana era escondernos entre las construcciones inmensas y vacías. El chiste era cantar bajito en una sala y después correr hacia la otra. El canto guiaba la búsqueda. Otra cosa que podía ayudarte eran los ladridos del perro. El perro siempre seguía a mi hermana, entonces era más fácil para mí dar con ella. Pero la verdad era que yo hacía lo posible por no encontrarla; prefería quedarme mirando las construcciones, las paredes altas y enmohecidas, algunas con enredaderas silvestres o manchadas de óxido. Prefería salir de una habitación y encontrarme de pronto en el río: era como estar dentro de una publicidad, muy irreal. Es un recuerdo verdusco el que guardo, será el moho... Lo que quiero decir es que éramos felices, al menos yo era muy feliz, en medio de tanta humedad (Quirós 167-68).

La ficción infantil inventa un modo de habitar esos espacios al parecer abandonados por el tiempo. Un modo de detención pacífica a la medida de las concepciones estéticas de la novela, pero esta vez una contemplación que paraliza el suspenso de la persecución, es decir se sustrae de la aceleración del entramado policíaco-criminal, sin por ello olvidarlo (el río al que miran los galpones es donde la hermana de Ema corre peligro de muerte y donde luego se arrojan los cadáveres y los suicidas, su flujo es el receptáculo de 
todos los cadáveres). Una forma de la felicidad, sobre la base de revitalizar aquello que el vértigo del tiempo ha descartado a su paso ${ }^{13}$.

En la misma clave, Bajo este sol tremendo imagina en la vivienda que Cetarti recibe de su hermano una posibilidad de residencia. Como en la novela de Quirós, el resguardo no puede obtenerse simplemente cerrándole la puerta a la brutalidad: la casa está ubicada en el barrio Hugo Wast, en homenaje al político y ensayista fascista argentino, y cerca del matadero municipal, con lo que no hay modo de simplemente dejar la violencia afuera. Por lo demás, sobradamente lo han entendido los protagonistas de la novela a través de los galgos que cuidan la casa de la madre de Danielito, que pasan fácilmente de proteger a atacar a la dueña de casa; una habitación defendida por medio de la seguridad no es sino la prolongación de los flujos de la violencia ${ }^{14}$. No hay lugar para Kevin McCallister.

La dimensión de la propiedad privada es irrelevante para la constitución de la morada, Cetarti ignora si la casa que ha heredado de su hermano realmente era suya, la había usurpado o se la había cedido el gobierno (Busqued 94-5);

13 Por una feliz convergencia terminológica, Kathleen Lowrey ha hablado del "host space" como realización espacial decisiva del modo de vida colectivo de las comunidades guaraníes del Chaco boreal (Lowrey passim). De esa manera ha querido enfatizar la lógica territorial que otras lecturas del ensayo excepcional de Pierre Clastres, La société contre l'État, han ignorado. Muy en particular, las investigaciones de Lowrey sirven de objeción al modo en que Deleuze y Guattari transforman las tesis de Clastres sobre las comunidades guaraníes del Chaco boreal en un modo de concebir las relaciones entre nomadismo y Estado (Deleuze y Guattari 441-6); lo que descuida Mille platteaux, más allá de omitir la especificación regional, es la lógica del espacio que el ensayo de Pierre Clastres sugiere y que los trabajos de Hélène Clastres hacen aun más visible. En efecto, según ha destacado Lowrey, las investigaciones de los Clastres sobre el Chaco implican una peculiar configuración territorial para la que la investigadora canadiense sugiere el concepto de "host space”. La organización colectiva guaraní precisa para enfrentarse a las instituciones represivas y las coerciones económicas constituir una residencia de la enunciación comunitaria, aquel territorio específico, sin delimitar pero localizado, que designan en la conjunción de las palabras ñemboatí -'reunirse'-y oyemboyovake -'enfrentarse con palabras'-(Lowrey 887-9), aquel sitio en el entramado espacial en el que detenerse para guarecer la interlocución política. Debe señalarse, con todo, que frente al implícito derridianismo con el que ella describe los host spaces en virtud de la presencia de demarcaciones ausentes, interesa más para la perspectiva del texto presente la efectiva presencia de unas prácticas del espacio (como ñemboatí y oyemboyovake, precisamente) que lo instauran.

14 En términos de Henri Lefebvre, "Espacio abstracto y violencia van juntos”: el espacio producido por sustracción técnica de las contradicciones -en nuestro contexto, de las amenazas- implica el ejercicio de la crueldad (224). 
lo único seguro es que la ocupaba con su colchón y su pecera con un ajolote, se hace propia por la vida que se despliega y el trabajo que se invierte sobre los deshechos que la pueblan, sea acumulándolos u ordenándolos. Certati se consagra a anidar, to nest, a hacerse un hábitat reparador, un lugar donde leer las revistas que valgan la pena, donde dormir y comer. Un lugar en el que si viniera un elefante homicida a golpear la puerta, en lugar de asesinar a los residentes acaso se persuadiría más bien de acercarse "con clama y cierta curiosidad” y tocarlos “suavemente con la trompa”, como en la fantasía de Danielito (Busqued 73). El elefante homicida está, en efecto, suelto, pero nada se resuelve si cuando decida visitar no se le abre la puerta (bien puede tirarla abajo); la única esperanza es haber inscrito un espacio de habitación, una condición de lectura, que le haga posible al elefante cambiar de planes.

La aparición del género negro en el Chaco argentino señala y forma parte de una compleja mudanza histórica en los modos de circulación de la violencia y de intervención sobre ella, que implica transformaciones en las configuraciones subjetivas y del espacio. La sustitución del cuchillero afamado por el homicida apologético converge con la aceleración de los flujos territoriales y la deslocalización de los agentes sociales, en las que resulta implicado un cambio en la explotación social de la narración. Los relatos dependen de ese proceso y satisfacen algunos de los requisitos que éste crea; pero al mismo tiempo toman partido por la instauración de formas de habitación en común que enfrenten la lógica de la violencia, sin desconocer la naturaleza del terreno experiencial sobre el que interceden. Los cuentos de Narradores actuales del Nordeste y de Carmen Lila Quevedo, y las novelas de Giardinelli, Busqued y Quirós inventan moradas contra la violencia porque se reconocen parte de su trama.

\section{BIBLIOGRAFÍA}

Agamben, Giorgio. "El autor como gesto”. Profanaciones. Trad. de F. Costa y E. Castro. Buenos Aires: Adriana Hidalgo, 2005. 84-90.

Busqued, Carlos. Bajo este sol tremendo. Buenos Aires: Anagrama, 2009.

Calvo, Claudia. "Memorias y Representaciones Sociales sobre el pasado reciente en el monte

Chaqueño”. Ponencia en las X Jornadas de sociología de la UBA, 1 al 6 de julio de 2013.

De Certeau, Michel. La invención de lo cotidiano. 1. Artes del hacer. Trad. de A. Pescador. México D. F.: Universidad Iberoamericana, 2000.

Deleuze, Giles y Félix Guattari. Mille plateaux. París: Éditions de Minuit, 1980. 
Foucault, Michel. Seguridad, territorio, población. Trad. de H. Pons. Buenos Aires: FCE, 2006. Vigilar y castigar. Trad. de A. Garzón del Camino. Buenos Aires: Siglo XXI, 2002. “La vida de los hombres infames”. La vida de los hombres infames. Trad. de J. Varela y F. Álvarez Uría. Buenos Aires: Caronte, 1996. 121-138. “Qu'est-ce qu'un auteur?”. Dits et écrits. Paris: Gallimard, 1994. 789-820

Friera, Silvina. “Tierra caliente, literatura valiente”. Página/12. 7383 (2 de febrero de 2009): 52.

Giachetti, Bruno. "Representaciones de subjetividades y espacios marginales en Bajo este sol tremendo de Carlos Busqued”. Ponencia en el V Congreso Internacional de Letras, Universidad de Buenos Aires, 27 de noviembre al 1 de diciembre de 2012.

Giardinelli, Mempo. Luna caliente. Barcelona: Bruguera, 1986.

Iñigo Carrera, Nicolás y Jorge Podestá. Movimiento social y alianza entre obreros y campesinos. Chaco (1934-1936). Buenos Aires: CEAL, 1991.

Jameson, Fredric. The Political Unconscious. Narrative as a Socially Symbolic Act. Ithaca: Cornell UP, 1982.

Lefebvre, Henri. “La producción del espacio”. Papers: Revista de Sociología 3 (1974): 52-67. Registro de traducción simultánea.

Link, Daniel (comp., pról. y col.). El juego de los cautos. Buenos Aires: La Marca, 1992.

Lowrey, Kathleen. "Ethics, Politics, and Host Space: A Comparative Case Study from South American Chaco”. Comparative Studies in Society and History. 53, 4 (2011): 882-913.

Ludmer, Josefina. "El cuerpo del género y sus límites. Ensayo para la construcción de un contexto y un sistema de objetos". El género gauchesco. Un tratado sobre la patria. Buenos Aires: Sudamericana, 1988. 11-130.

Mari, Oscar E. "Inseguridad y bandidaje en el territorio nacional del Chaco. 1918-1940", Cuadernos de Geohistoria Regional. 30 (1994).

Mateus, Sebastián. “Desesperación y salvajismo sexual en Luna Caliente, de Mempo Giardinelli”. Sin pretextos Mayo 2013 sinpretextos.com/literatura/item/373-desesperaci\%C3\%B3n-ysalvajismo-sexual-en-luna-caliente-de-mempo-giardinelli

Muscar Bensayag, Eduardo, Elena Alfonso y Daniela Torrente. "La industria maderera en la provincia de Chaco como estímulo al desarrollo local”. Folia Histórica del Nordeste 13 (2011): 245-68.

Natanson, Daniel. “Tres tesis sobre el territorio”. Le monde diplomatique 164 (febrero de 2013): 2-3.

Nichols, William John. "Siguiendo las pistas de la novela negra con Mempo Giardinelli". Revista Iberoamericana 76, 231 (abril-junio de 2010): 57-62.

Pablos, Ricardo. "“Me gusta la literatura que se escribe con urgencia'”. La Voz del Interior Marzo 2012 vos.lavoz.com.ar/libros/me-gusta-literatura-que-se-escribe-con-urgencia

Paredes, Ricardo Iván. “Mariano Quirós: 'Me gusta la idea de un lector que molesta, capaz de leer en lugares imposibles"”. Pliego suelto Octubre 2013 pliegosuelto.com/?p=8602

Pérez Chávez, Osvaldo (comp.). Narradores actuales del Nordeste. Buenos Aires: Nueva Tierra, 1971. 
Quevedo, Carmen Lila. “La respuesta”. Llamada María. Resistencia: Banco de la Provincia de Chaco, 1969. 31-38

Quirós, Mariano. Río Negro. Buenos Aires: Gárgola, 2011.

Selci, Damián. “Minimalismo y violencia”. Otra parte 24 (primavera de 2011).

$\mathrm{S} / \mathrm{F}$. "La literatura chaqueña pasa por un momento muy importante" (entrevista a Mariano Quirós). Chaco Día por Día Enero 2012 chacodiapordia.com/noticia.php?n=53546

Serres, Michel. Atlas. Paris: Julliard, 1994.

Setton, Román. Los orígenes de la narrativa policial en la Argentina. Madrid: Iberoamericana, 2012.

Speranza, Graciela. “Mundo animal”. Otra parte 18 (primavera de 2009).

Stegmayer, María y María Fernanda González. “Algunas notas sobre Bajo este sol tremendo, de Carlos Busqued”. Orbis Tertius 17 (2011).

Terranova, Juan. “Catálogo natural y altura en Busqued”. Los gauchos irónicos. Buenos Aires: Milena cacerola, 2013. 33-51.

Williams, Raymond. El campo y la ciudad. Trad. de A. Bixio. Buenos Aires: Paidós, 2001.

Zubieta, Ana María. "La novela negra como fuente”. Revista de la UNAM. 38, 21 (enero de 1983): 43-46.

Zunini, Patricio. "Los que ganaron en el fin del mundo". Blog Eterna Cadencia Marzo 2011. $<$ blog.eternacadencia.com.ar/ archives/2011/12742>. 